\title{
A new species of Seira (Collembola: Entomobryidae) from northeastern Brazil
}

\author{
Bruno C. Bellini ${ }^{1,3} \&$ Douglas Zeppelini ${ }^{2}$ \\ ${ }^{1}$ Laboratório de Invertebrados Paulo Young, Departamento de Sistemática e Ecologia, Centro de Ciências Exatas e da \\ Natureza, Universidade Federal da Paraíba. Campus I, 58059-900 João Pessoa, Paraíba, Brasil. \\ E-mail: entobellini@yahoo.com.br \\ ${ }^{2}$ Centro de Ciências Biológicas e Sociais Aplicadas, Universidade Estadual da Paraíba. Campus V. João Pessoa, Paraíba, Brasil. \\ ${ }^{3}$ Corresponding author.
}

\begin{abstract}
A new species of Seira Lubbock, S. mendoncea sp. nov., from Cacimba de Dentro, state of Paraíba, Brazil is described and illustrated. The new species resembles $S$. delamarei Jacquemart in many morphological features, especially on the dorsal macrochaetae disposition. In Brazil there are now 21 described species of Seira, with 12 of them recorded in Paraíba.
\end{abstract}

KEY WORDS. Brazilian collembolan diversity; caatinga; chaetotaxy patterns; Seirinae.

\begin{abstract}
RESUMO. Uma nova espécie do gênero Seira Lubbock, S. mendoncea sp. nov., coletada no município de Cacimba de Dentro, Estado da Paraíba, Brasil, é descrita e ilustrada. A nova espécie possui muitas semelhanças morfológicas com S. delamarei Jacquemart, especialmente no que se refere à disposição das macroquetas dorsais. No Brasil há até o momento 21 espécies descritas de Seira, com 12 espécies registradas na Paraíba.
\end{abstract}

PALAVRAS-CHAVE. Caatinga; diversidade brasileira; padrões de quetotaxia; Seirinae.

Entomobryidae is the largest family of Collembola, with more than 1625 described species (Bellinger et al. 1996-2008). Seira Lubbock, 1869 is one of the most diverse genera of the family, comprising 178 species (BELLINGER et al. 1996-2008, MARI Mutt \& Bellinger 1990, 1996, Mari Mutt et al. 1998-2008, Bellini \& ZepPeLINI 2008).

The habitus of Seira specimens are similar to other entomobryids (Christiansen \& BelLINGer 1998). The genus can be distinguished by the presence of a falcate mucro, eight or seven lenses on each eye spot and yellowish or brownish rounded scales covering the dorsum of the head, body and at least the first segments of antennae, legs and furca (CHRISTIANSEN \& Bellinger 2000, Barra 2004).

The majority of Seira species has been recorded from the tropical areas, and the species are usually found in warm locations (Mari Mutt et al. 1998-2008, Christiansen \& Bellinger 2000, Zeppelini \& Bellini 2006, Bellini \& Zeppelini 2008). There are 48 species of Seira described for the Americas, 20 of which being recorded in Brazil (Mari Mutt 1986, Culik \& Zeppelini 2003, BeluinI \& Zeppelini 2005, 2008, Zeppelini \& Bellini 2006). In Brazil, Seira is the most diverse known genus of Collembola, along with Sphaeridia (Culik \& Zeppelini 2003, Bellini \& Zeppelini 2008).

Herein a new species of Seira is described, collected in Cacimba de Dentro, state of Paraíba, northeastern Brazil. The chaetotaxy system used follows Christiansen \& Bellinger (2000), modified from JACQUEMART (1974).

\section{MATERIAL AND METHODS}

The specimens were collected at the Fazenda Cachoeira da Capivara, in Cacimba de Dentro, state of Paraíba, Brazil, in January of 2008, during the dry season, directly from the soil and foliage using entomological aspirators.

The specimens were mounted on glass slides with Hoyer's solution following Christiansen \& BeLLINGER (1998).

\section{RESULTS AND DISCUSSION}

\section{Seira mendoncea sp. nov.}

Figs 1-11

Etymology. The species was named after Maria Cleide de Mendonça, one of the most important Collembola researchers in Brazil.

Total length of the holotype $1,48 \mathrm{~mm}$, other measures are listed in table I. Habitus typically entomobryid (Figs 1 and 2). Color of fixed specimens pale yellow with dark blue pigment covering the antennae, fore-head, lateral borders of meso and metathorax, abd I, III, IV and V (Fig. 1); mounted specimens - pale grey with dark blue pigment covering antennae, fore-head, lateral borders of meso and metathorax, abd I, III, IV and V (Fig. 2). Brownish rounded scales covering Ant. I, II and III, head, meso and metathorax, abdomen, coxae, trochanters, femurs and tibiotarsus, manubrium and dens. Ant. IV not 


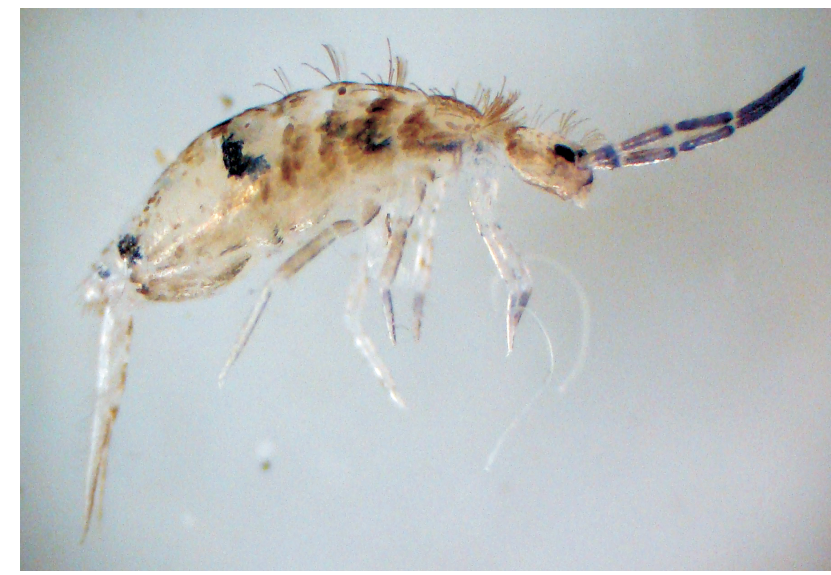

Figure 1. Seira mendoncea sp. nov. Habitus of a preserved specimen.

annulated, with an apical bulb and no pin setae (Fig. 4). Eye patches oval, with the largest lens being $\mathrm{B}$ and the smallest lens being $\mathrm{H}$, with four interocular feathered setae (Fig. 5). Prelabral and labral setae feathered. Labial triangle seta $\mathrm{r}$ reduced. M1, M2 and E feathered (Fig. 3). Trochanteral organ in inverted V-shape with 24 spine like setae (Fig. 5). Pro, meso and meta ungues with four inner teeth, one pair at base and two unpaired teeth at apex (Figs 7-9). Unguiculi acuminate, with slightly smooth edges (Figs 7-9). Tenent hair capitate with smooth edges. Venter of manubrium with five subapical setae. No spine-like setae on manubrium. Mucro tipically falcated (Fig. 10). Dorsal macrochaetae distribution of head and body as in figure 11. Other characteristics are listed in table II.

Taxonomic Summary. Holotype. BraziL, Paraíba: Cacimba de Dentro (Fazenda Cachoeira da Capivara), male, 27-I-2008, B. Bellini leg. Paratypes: 3 males, 9 females, with the same data as the holotype. The type material is deposited at the Museu Nacional, Universidade Federal do Rio de Janeiro, Rio de Janeiro, Brasil (CM/MNRJ).
Table I. Lengths of segments of the body of S. mendoncea sp. nov. Measurements were taken from holotype. Conversion rate to $\mu \mathrm{m}=\mathrm{x} 10$.

\begin{tabular}{lc}
\hline \multicolumn{1}{c}{ Segments } & S. mendoncea \\
\hline Antenna Segment IV & 27 \\
Ant. III & 19 \\
Ant. II & 17 \\
Ant. I & 9 \\
Head length & 35 \\
Head (cephalic diagonal) & 38 \\
Mesothorax & 24 \\
Metathorax & 13 \\
Abdominal Segment I & 8 \\
Abd. II & 12 \\
Abd. III & 17 \\
Abd. IV & 51 \\
Abd. V & 9 \\
Abd. VI & 6 \\
Manubrium & 32 \\
Dens & 41 \\
Mucro & 1 \\
\hline
\end{tabular}

Remarks. The head chaetotaxy of $S$. mendoncea sp. nov. resembles that of $S$. delamarei Jacquemart, 1980, a species only found in Ecuador (Christiansen \& Bellinger 2000). Cephalic regions $2,4 \mathrm{~A}, 4 \mathrm{C}$ and 6 of both species have the same number of macrochaetae in the same disposition. Regions 1 and 5 have also some similarities. The number and disposition of macrochaetae at the cephalic region 4 of $S$. mendoncea sp. nov. is similar to $S$. dubia Christiansen \& Bellinger, 1980 and S. mantis Zeppelini \& Bellini, 2006, with two macrochaetae at region $4 \mathrm{~A}$, four at $4 \mathrm{~B}$ and three at $4 \mathrm{C}$. The chaetotaxy pattern of the thorax of $S$. mendoncea sp. nov. resembles that of $S$. delamarei,

Table II. Comparison of characters among species of Seira.

\begin{tabular}{lcccc}
\hline \multicolumn{1}{c}{ Species } & $\begin{array}{c}\text { Lobes on antennal apical } \\
\text { bulb }\end{array}$ & $\begin{array}{c}\text { Clear annulations on 4th } \\
\text { antennal segment }\end{array}$ & $\begin{array}{c}\text { Ratio antenna/cephalic } \\
\text { diagonal }\end{array}$ & Unguiculus shape \\
\hline S. mendoncea $^{*}$ & 1 & - & 1.89 & Acuminate \\
S. delamarei & 2 & - & $2.3-2.7$ & Acuminate \\
S. dubia & 2 & + & $3.0-4.5$ & Acuminate \\
S. mantis & 2 & + & 3.33 & Acuminate \\
\hline \multicolumn{1}{c}{ Species } & Number of inner & Distinctly larger inner & Spine-like setae at base of Number of ventral manubrial \\
subapical setae
\end{tabular}

(A-) Minor apical, (M+) larger medial, (+) present, $(-)$ absent, $\left(^{*}\right)$ measurements were taken from holotype. 

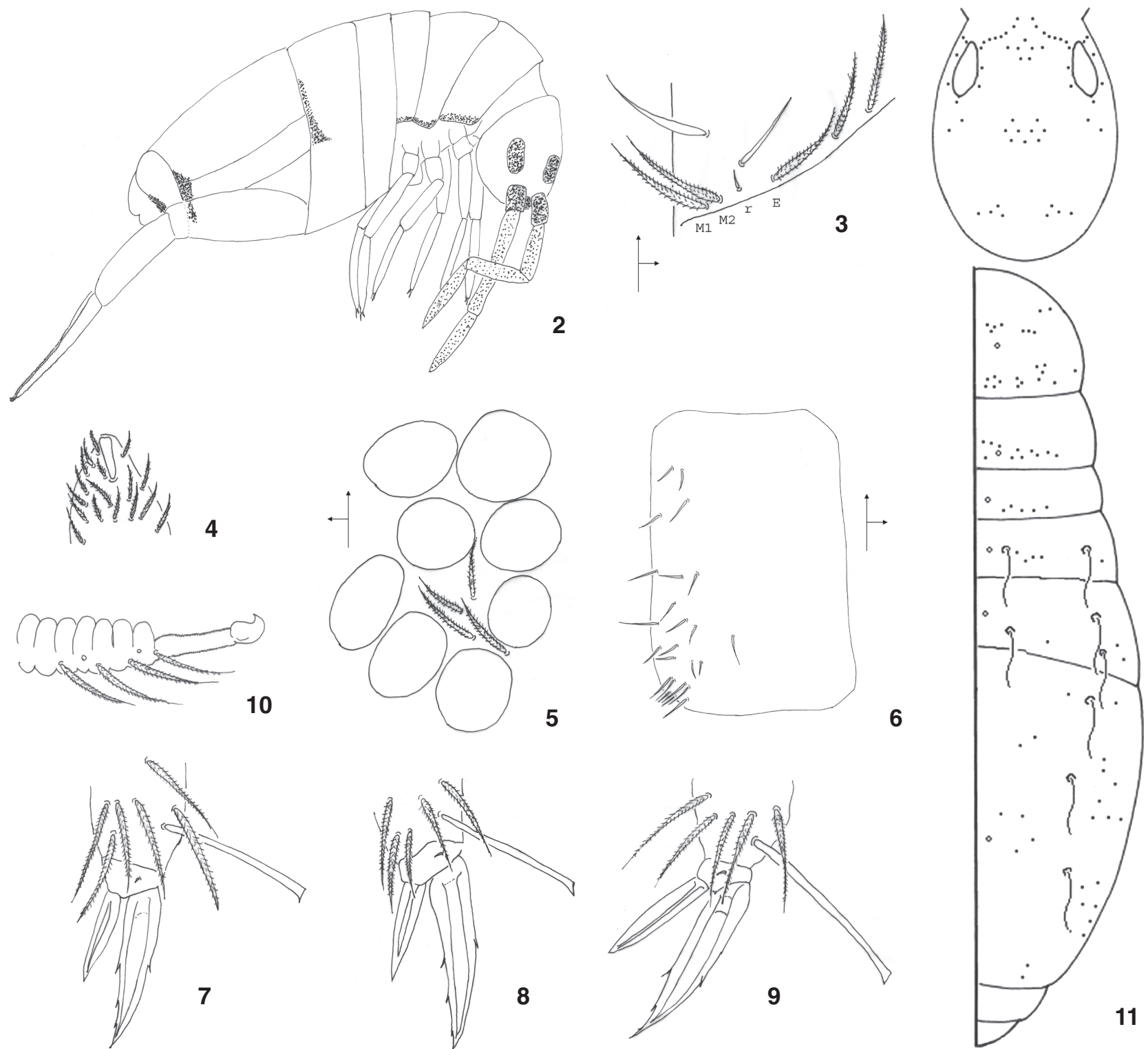
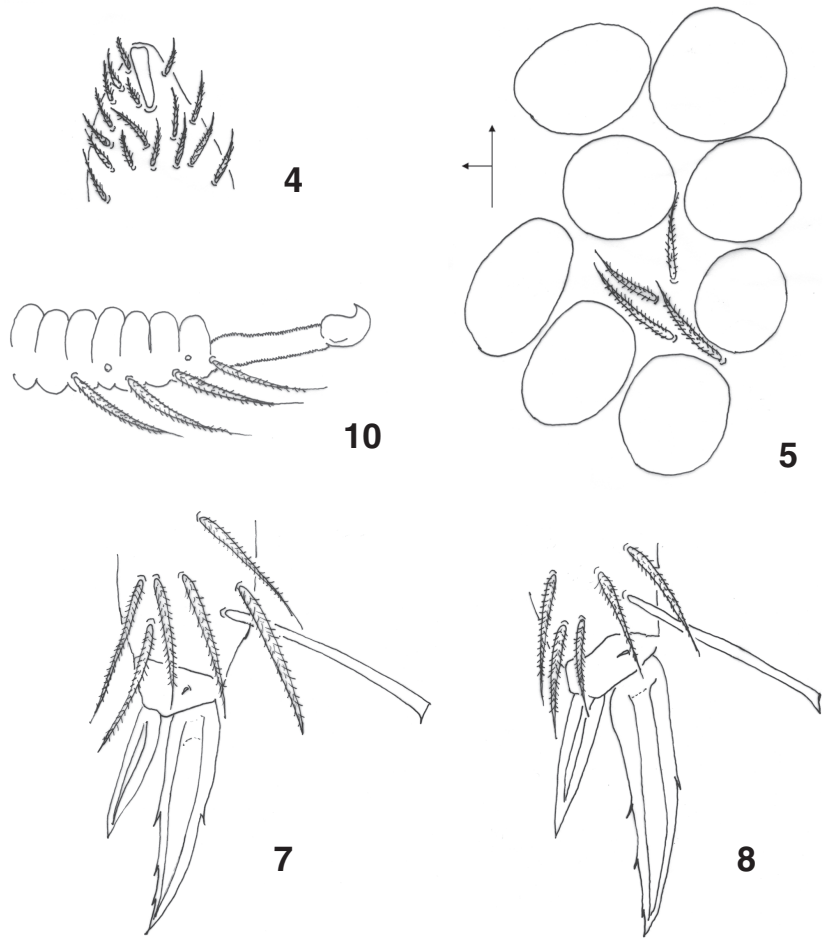
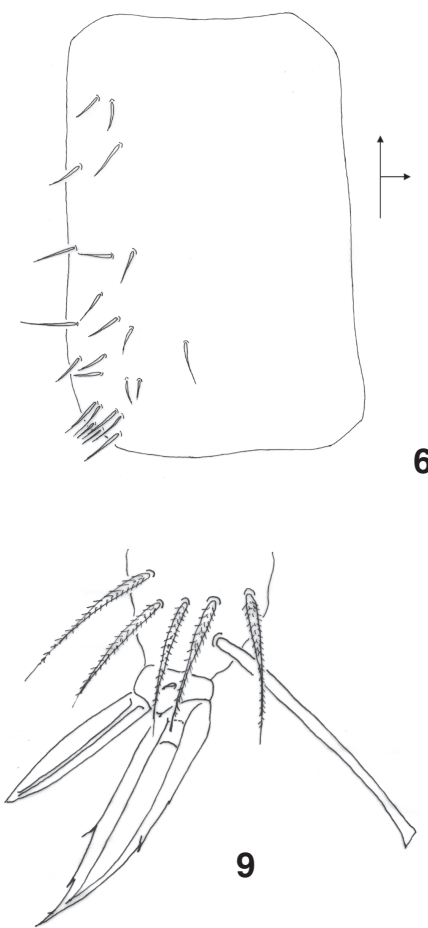

11

Figures 2-11. Seira mendoncea sp. nov.: (2) habitus; (3) labial quaetotaxy; (4) apical bulb of $4^{\text {th }}$ antennal segment; (5) right eye patch; (6) metatrochanteral organ; (7) first foot complex; (8) second foot complex; (9) third foot complex; (10) distal dens and mucro; (11) dorsal macrochaetae distribution.

especially at regions 2 and $3 \mathrm{~A}$ at the mesothorax and region $\mathrm{A}$ and $\mathrm{B}$ of the metathorax. There are five macrochaetae on the first abdominal segment of $S$. mendoncea sp. nov. in contrast to three or four found in $S$. delamarei. Abdominal segments II and III have also similarities between the two species. The Abd. IV on the species differs considerably, and this segment in $S$. mendoncea sp. nov. appears more similar to that of $S$. mantis. The shape of the feet complexes and antennae is similar in $S$. mendoncea sp. nov. and $S$. delamarei (Tab. II). Other characteristics are compared in table II.
Seira mendoncea sp. nov. was collected at Cacimba de Dentro, state of Paraíba, Brazil. The climate of the type locality is 'As' following Koeppen's system (Коттек et al. 2006) and it is located at the biogeographic zone 27 (Good 1974). This region is situated between Caatinga and Brejo de Altitude biomes. In the same locality occur other three species of Seira: S. raptora Zeppelini \& Bellini, 2006, S. nigrans (Arlé, 1959), and S. mirianae Arlé \& Guimarães, 1981.

A total of 12 species of Seira have been recorded in Paraíba so far, including S. mendoncea sp. nov. (BelLinI \& Zeppelini 2005, 
2008, Zeppelini \& Bellini 2006). In Brazil there are now 21 described species.

\section{ACKNOWLEDGEMENTS}

Support for this study was provided by a grant to the senior author by $\mathrm{CNPq} / \mathrm{MCT} /$ Brazil.

\section{LITERATURE CITED}

BARRA, J.A. 2004. Le genre Seira (Collembola, Entomobryidae) du Yémen continental. Zoosystema 26 (2): 291-306.

Beluini, B.C. \& D.F. Zeppelini. 2005. First records of Collembola (Ellipura) from the state of Paraíba, Northeastern Brazil. Revista Brasileira de Entomologia 48 (4): 587-588.

Bellini, B.C. \& D. Zeppelini. 2008. Three new species of Seira Lubbock (Collembola, Entomobryidae) from Mataraca, state of Paraíba, Brazil. Zootaxa 1773: 44-54.

Bellinger, P.F.; K.A. Christiansen \& F. Janssens. 1996-2008. Checklist of the Collembola of the World. Available online at: http://www.collembola.org [Accessed: June 2008].

Christiansen, K. \& P. Bellinger. 1998. The Collembola of North America North of the Rio Grande. Grinnell, Grinnell College, 1322p.

Christiansen, K. \& P. Bellinger. 2000. A survey of the genus Seira (Collembola: Entomobryidae) in the Americas. Caribbean Journal of Science 36 (1-2): 39-75.

Culik, M. \& D.F. Zeppelini. 2003. Diversity and distribution of
Collembola. (Arthropoda: Hexapoda) of Brazil. Biodiversity and Conservation 12: 1119-1143.

Good, R. 1974. The geography of flowering plants. London, Longman Group, $4^{\text {th }}$ ed., $574 \mathrm{p}$.

JACQUEMART, S. 1974. Resultats de la mission Anthropologique Belge au Niger. Collemboles nouveaux du Sahara. Bulletin del'Institute royal dês Sciences naturelles de Belgique 49: 1-16.

Kotter, M.; J. Grieser; C. Beck; B. Rudolf \& F. Rubel. 2006. World Map of the Köppen-Geiger climate classification updated. Meteorologische Zeitschrift 15 (3): 259-263.

Mari Mutt, J.A. 1986. Puerto Rican species of Seira (Collembola: Entomobryidae). Caribbean Journal of Science 22 (3-4): 145-158.

Mari Mutt, J.A. \& P.F. Bellinger. 1990. A catalog of the Neotropical Collembola. Gainsville, Sandhill Crane Press, Flora \& Fauna Handbook no. 5, 237p.

Mari Mutt, J.A. \& P.F. Bellinger. 1996. Supplement to the Catalog of the Neotropical Collembola - August 1989 to April 1996. Caribbean Journal of Science 32: 166-175.

Mari Mutt, J.A.; P.F. Bellinger \& F. Janssens. 1998-2008. Supplement to the Catalog of the Neotropical Collembola. Available online at: http://www.collembola.org/publicat/ neotrcat.htm [Accessed: June 2008].

Zeppelini, D.F. \& B.C. Bellini. 2006. Two Seira Lubbock 1869 (Collembola, Arthropleona, Entomobryidae) new to science, with remarkable secondary sexual characters. Zootaxa 1185: 21-35.

Submitted: 20.VI.2008; Accepted: 01.XII.2008.

Editorial responsibility: Claudio J.B. de Carvalho 